\title{
Sharing resources in Finnish university libraries: reorganising the national document supply system
}

\author{
Ari Muhonen \\ Helsinki University of Technology Library, TKK, Finland \\ Annu Fauhiainen \\ National Library of Finland, Helsinki University, Helsinki, Finland \\ Pentti Vattulainen \\ National Repository Library, Kuopin, Finland
}

\begin{abstract}
Purpose - To describe the development of interlending and document supply (ILDS) in Finland and the recent initiative to move to patron initiated ILDS.

Design/methodology/approach - Historical narrative and analysis.

Findings - That ILDS in Finland is declining primarily because of the "Big Deals" and the introduction of ILDS charges after the privatisation of the postal service. That Finland needs to move to a more developed patron initiated culture for the supply of documents to users.

Practical implications - The need for further ILDS software development has been identified in order to underpin unmediated ILDS; this will be progressed during 2006.

Originality/value - Provides information on the current ILDS situation in Finland and to a lesser extent other Nordic countries. Provides an insight into how a European country is moving towards unmediated ILDS.
\end{abstract}

Keywords Academic libraries, Finland, Document delivery

Paper type General review

\section{Introduction}

University libraries form the core for dissemination of scientific information in Finland. The 21 universities in ten different cities cover the country well. Their regional influence is strong since they are open to all users, not just students and researchers. However, many of the universities are rather young and small their libraries having only limited collections. Therefore interlibrary lending and document supply (ILDS) is vital for compensating this shortcoming. However, there is no central organization in Finland which would guide the development of ILDS. Instead, many institutions carry the responsibility for their own activities.

For the past 15 years Finnish university libraries have waited for the automation of the key ILDS functions. They have had the advantage of using a joint library management system (ILS) since the early 1990s. It was agreed that an ILDS module would be included but was never obtained. When the old ILS was replaced with (Voyager) in 2001 an ILDS module was again not included. At the time it was thought that there was enough work to convert the databases

The current issue and full text archive of this journal is available at www.emeraldinsight.com/0264-1615.htm

Interlending \& Document Supply

34/2 (2006) 51-56

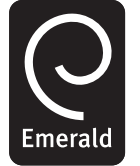

(C) Emerald Group Publishing Limited [ISSN 0264-1615]

[DOI 10.1108/02641610610669732] and the existing functionalities to the new system. The plan was to come back to this issue once everything else was up and running. Meanwhile some libraries developed their own ILDS software while others continued the traditional manual work.

The integrated library management system is one of the corner stones in the technical infrastructure for the Finnish library network, the Digital Library of Finland (the "Triangle"), which consists of three modules: ILS (Voyager), the portal software (MetaLib/SFX) for accessing remote and local databases and other electronic resources, and the Digital Objects Management system (ENCompass). The goal is that these three applications would communicate and work seamlessly together, as well as with other applications, via application program interface's and using open standards. In addition to the three main components, the vision is to add other applications to fulfil the needs of the libraries and their users; one of those applications is the ILDS software.

In the spring of 2004 the Linnea2 Consortium (responsible for the ILS system) decided to form a working group for ILDS evaluation. Its aim was to evaluate the current state of ILDS in the Nordic countries, collect information on the

This article is a revised version of the paper given at the 9th IFLA Interlending and Document Supply (ILDS) International Conference held in Tallinn, Estonia, September 20-23, 2005.

This conference was sponsored by IFLA whose cooperation and agreement to publish is gratefully acknowledged. 
software packages in the market and make recommendations for the future of Linnea2 ILDS. This paper presents the results of the working group. It also gives some general background for the Finnish university libraries as well as their ILDS activities

\section{The Linnea network and Linnea2 Consortium}

Finnish university libraries have a long history of cooperation, especially in the field of cataloguing and library automation. Since 1977, the libraries used the FINMARC format and the LSP application purchased from the British Library for offline cataloguing and production of printed and microform catalogues. The main purpose of those catalogues was to the location function within ILDS. Online databases were built from this data by the early 1980s. The Automation Unit of Finnish Research Libraries, a unit within the Ministry of Education, established in 1974, coordinated the cooperation.

A new era started in the 1980s. The Ministry of Education funded a project to select a joint automated library system for all academic libraries. The contract with VTLS Inc. for the VTLS system was signed in 1988. A unified network called Linnea (Library INformation NEtwork for Academic libraries) was created in the early 1990 s consisting of local ILS installations and a common physical union catalogue which all were connected by the academic data transmission network FUNET. The VTLS software was used for a decade and replaced by a new system, Voyager, in 2001.

The Linnea cooperation was formalized in the year 2000 when 20 universities (including the National Library), the Library of Parliament and the National Repository Library established the Linnea2 Consortium. New institutions have joined later, the number of members being now 27 . According to the Consortium bylaws, most decisions, especially those dealing with money, have to be approved by the General Council, based on consensus. The National Library is the executive body, preparing all matters to the Steering Group and the General Council.

The Linnea libraries maintain 30 databases of which 24 are local OPACs, feeding into the physical union catalogue.

The union catalogue for the Finnish academic libraries, Linda, contains 4.6 million bibliographic records. The database includes references on monographs, serials, cartographic materials, audiovisual materials, electronic resources, multimedia and archives. Linda has played an essential role in uniting libraries and their databases. In addition to copy cataloguing, ILDS locating is very efficient, because Linda contains real time links to holdings and items in the contributing libraries.

\section{Development of ILDS in the university libraries}

The Finnish university libraries modernized their ILDS procedures in the early 1970s. Following this the Finnish Government decided to form a network of resource libraries in 1972. Their duty was to develop their collections in specific subject fields, make them accessible, carry out ILDS and provide information services. By 1985 ten resource libraries had been nominated covering all applied sciences and a major share of other fields of learning (Törnudd, 1993). In 1972 Finnish libraries also received their first ILDS handbook (Kurikka and Liinamaa, 1972). Also remarkable for the university libraries was their franking privilege. They were allowed to send letters and parcels free of charge among the libraries thus allowing for a free ILDS service.

This sound base guaranteed a steady growth of ILDS in university libraries during the 1980 s, as shown in Figure 1. The peak year was 1988 with close to 300,000 received requests. However, the situation changed in the early 1990s. A severe recession tightened the economic situation considerably. The universities lost their franking privilege when the Finnish post became a commercial state-owned company. This meant that ILDS had to become a fee-based service in 1993. As a result requests declined by about one third.

The resource library system lost its meaning gradually during the 1990s. The Ministry of Education gave more economic independence to the universities. This meant that it could no longer influence library budgets. Financial pressures and performance driven management led to libraries concentrating on their campus services. In addition, the internet meant that locating materials became possible for everybody and the services of the resource libraries were no longer needed. The Government discontinued the resource library system in 2003.

Since 1998 the number of requests has decreased consistently as shown in Figure 1. Two clear reasons can be found for this: the National Repository Library and the big deals acquired in Finland through FinELib.

The National Repository Library (NRL) [1] was founded by the Ministry of Education in 1989 as a common central storage for all Finnish libraries, scientific as well as public libraries. Its collection consists of material sent from other libraries. Currently it holds nearly one million books and over 71,000 journal titles comprising over one million volumes. Its ILDS procedures are very effective. Returnables are usually supplied within 24 hours. Non-returnables are sent by e-mail as pdfs. They are printed by the requested library and prints are sent to the end users. Technically it would be possible to send the pdfs straight to the end user. However, the copyright law presently prevents that.

As Figure 1 shows, the NRL has steadily increased its share of incoming requests. This is due to their free service; costs are covered by the Ministry of Education. The requesting libraries have to pay only for the return postage to the NRL of the returnables.

The purchase of electronic scientific journals through big deals has changed the journal acquisition of the university libraries considerably. This is done through FinELib, the National Electronic Library, a nation wide consortium for acquiring electronic material for its members 2 . This work began in 1997 as a project and was formalized in 2000. It is coordinated by the National Library of Finland. At the moment the number of member libraries is 108. The consortium receives some centralized funding from the Ministry of Education but most comes from the participating libraries.

FinELib has already negotiated dozens of contracts for the member libraries. They include almost all the biggest publishers as well as learned societies. The total number of acquired materials in 2004 was 19,500 electronic journals, 229 databases and 25,000 electronic books. However, all these are not available to all members. Each member decides itself which materials it wants to acquire. Thus FinELib is actually an umbrella for dozens of smaller consortia; further details can be found in (Hormia, 2004). 
Figure 1 Number of requests received annually by the university libraries and the National repository library

$\square$ University libraries, total $\square$ National repository library

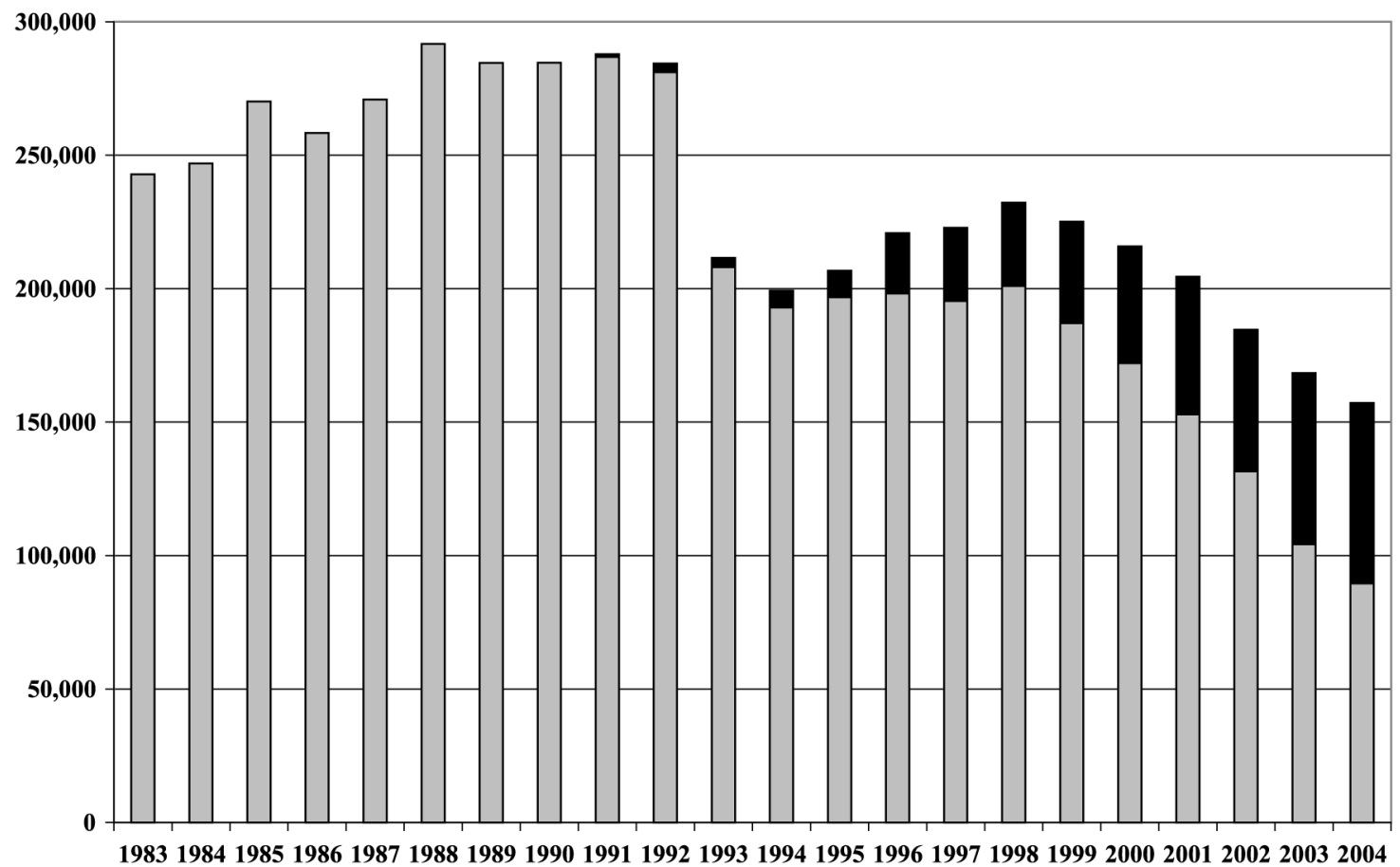

\section{Current situation}

Recent years have seen some significant changes in academic ILDS. Figures 2 and 3 show the ILDS volumes of returnables and non-returnables. Unfortunately the statistics show the separation only since 2002 , but the three year period 20022004 is very illuminating. The emphasis is laid on the ratios of the deliveries given by the NRL, domestic university libraries and foreign suppliers.
The overall number of the borrowing of returnables has slightly decreased during the period. The delivery ratios are quite steady. About 20 per cent of the returnables have been ordered from abroad. The rest is split quite evenly between the NRL and the domestic university libraries with some annual variation. However, the latest statistics (2005) from the NRL show an increase. Unfortunately the numbers from the university libraries are not yet available.

Figure 2 Number of returnables ordered by the Finnish university libraries 2002-2004 (2005)

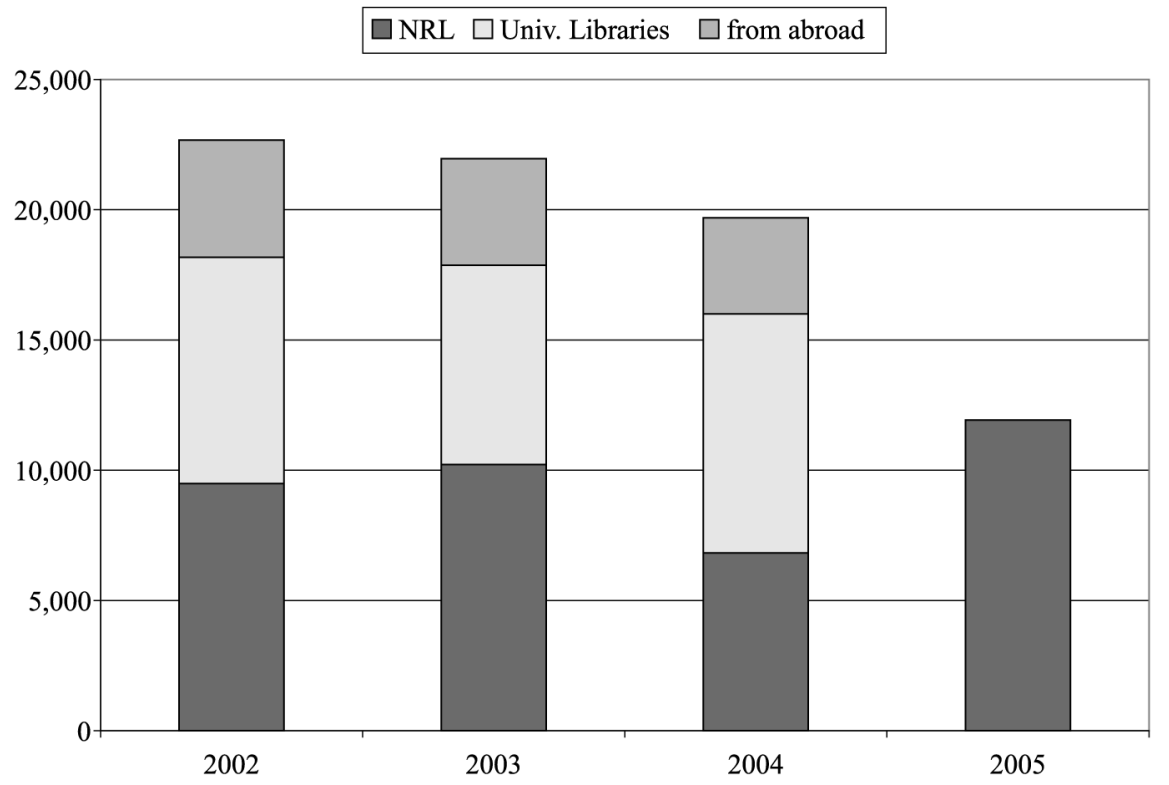


Figure 3 Number of non-returnables ordered by the Finnish university libraries 2002-2004

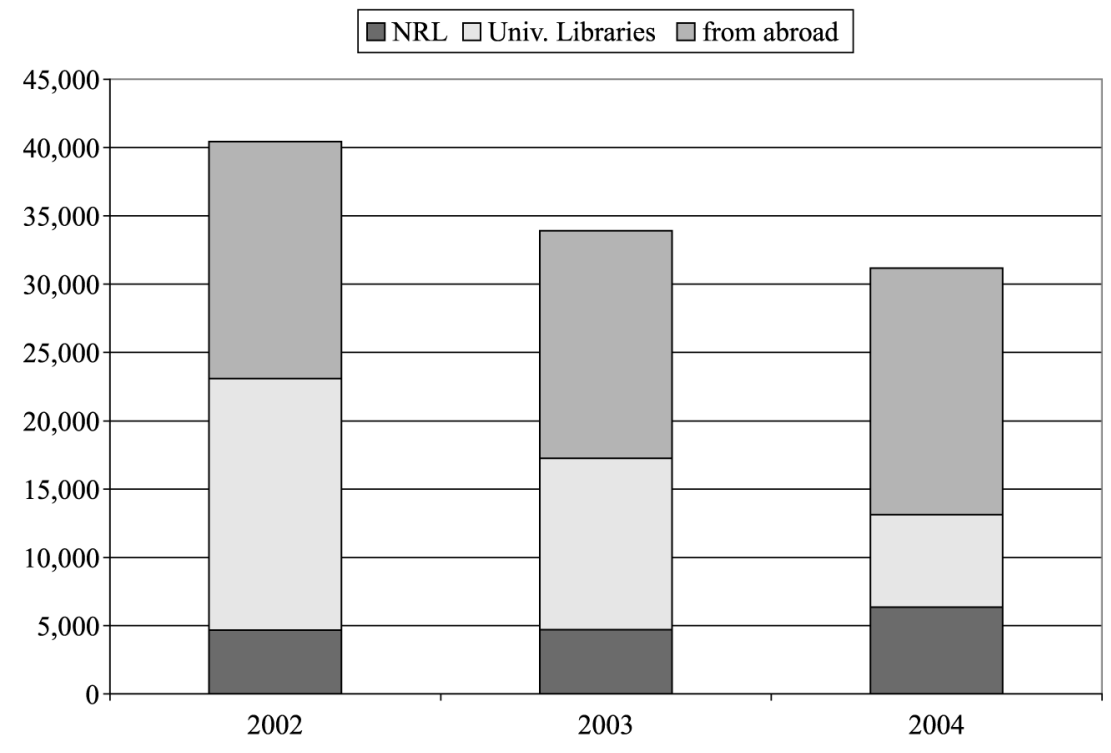

The statistics for non-returnables show some drastic changes. The overall number is clearly decreasing. Those of the university libraries have decreased 63 per cent between 2002 and 2004. During the same period both the NRL and the suppliers abroad have increased. The ratios show a clear change. In 2002 the university libraries supplied 45 per cent of the documents declining to 22 per cent in 2004. At the same time the ratios of the NRL and suppliers abroad increased from 12 per cent to 20 per cent and from 43 per cent to 58 per cent respectively.

The interpretation of these statistics is clear. Up to the 1990 s requests were sent to the university libraries and only if they could not fulfil them were they sent abroad. Nowadays the requests are first sent to the NRL, because the delivery is free of charge and fast. For the non-returnables the second choice is Subito or some other foreign supplier, because of their cheap and fast delivery. The domestic university libraries are in third place for non-returnables and second for the returnables. Money talks, not solidarity anymore.

\section{Comparison between the Nordic countries}

In order to promote resource sharing a Nordic performance study was conducted in 2000-2001. A report for Nordinfo Board was published in 2003 (Vattulainen, 2003). One of the motives of the study was to identify possible barriers to resource sharing with the goal of eliminating them. Several issues were identified.

Academic libraries are net lenders in all Nordic countries. This is due to their strong regional influence; they tend to lend a lot of material to the public libraries as well as private enterprises. However, the volume of ILDS differs considerably from one country to another. Figure 4 shows the number of incoming requests in the year 2000. Finland is far behind the Scandinavian countries Denmark, Norway and Sweden. This can also be seen in the ratio of incoming requests (returnables and non-returnables) vs home loans. The percentage is less than 2 in Finland whereas in the other Nordic countries it is more than 10 (Table I).
The study also showed that the share of books in ILDS is about 50 per cent in the Scandinavian countries, whereas in Finland it is only 25 per cent. However the unit costs in Finland were the highest except for Iceland. Thus the Finnish system with high fees creates problems especially in sharing books. In order to promote national resource sharing it is important to create structures that support the interlending of books.

In spite of these problems the study also revealed the advantages of the Finnish ILDS system. The speed of service was good, especially for article copies. The copyright legislation has been interpreted in Finland to allow electronic delivery methods. Another positive feature found was that the fill rate was high. This reflects good locating tools and a liberal lending policy - most catalogued material was actually available for interlending.

Both the overall request numbers and the Nordic study show that the ILDS system within the Finnish university libraries is not efficient with fees being a major hindrance. However fees cannot be avoided due to government policy. Another problem is the amount of manual work. The Linda database is the only Nordic union catalogue which lacks an ILDS facility. Therefore Linda can only be used for locating and the request has to be sent via e-mail or a separate web form. Finally, the lack of proper software compels ILL staff to retype the same information many times, thus making their work inefficient.

\section{Challenges}

Finnish university libraries are facing a big challenge: they should reorganize their ILDS functions in order to keep their position as net lenders (and thus keep their income from the transactions) and as ILDS libraries in general. The traditional "from library to library" ILDS has already been abandoned in many cases in the other Nordic countries and the patron initiated unmediated ILDS has gained ground. In some cases books can even be delivered directly to the patron from the lending library. 
Figure 4 Volume of incoming requests in the Nordic countries in 2000 (Vattulainen, 2003)

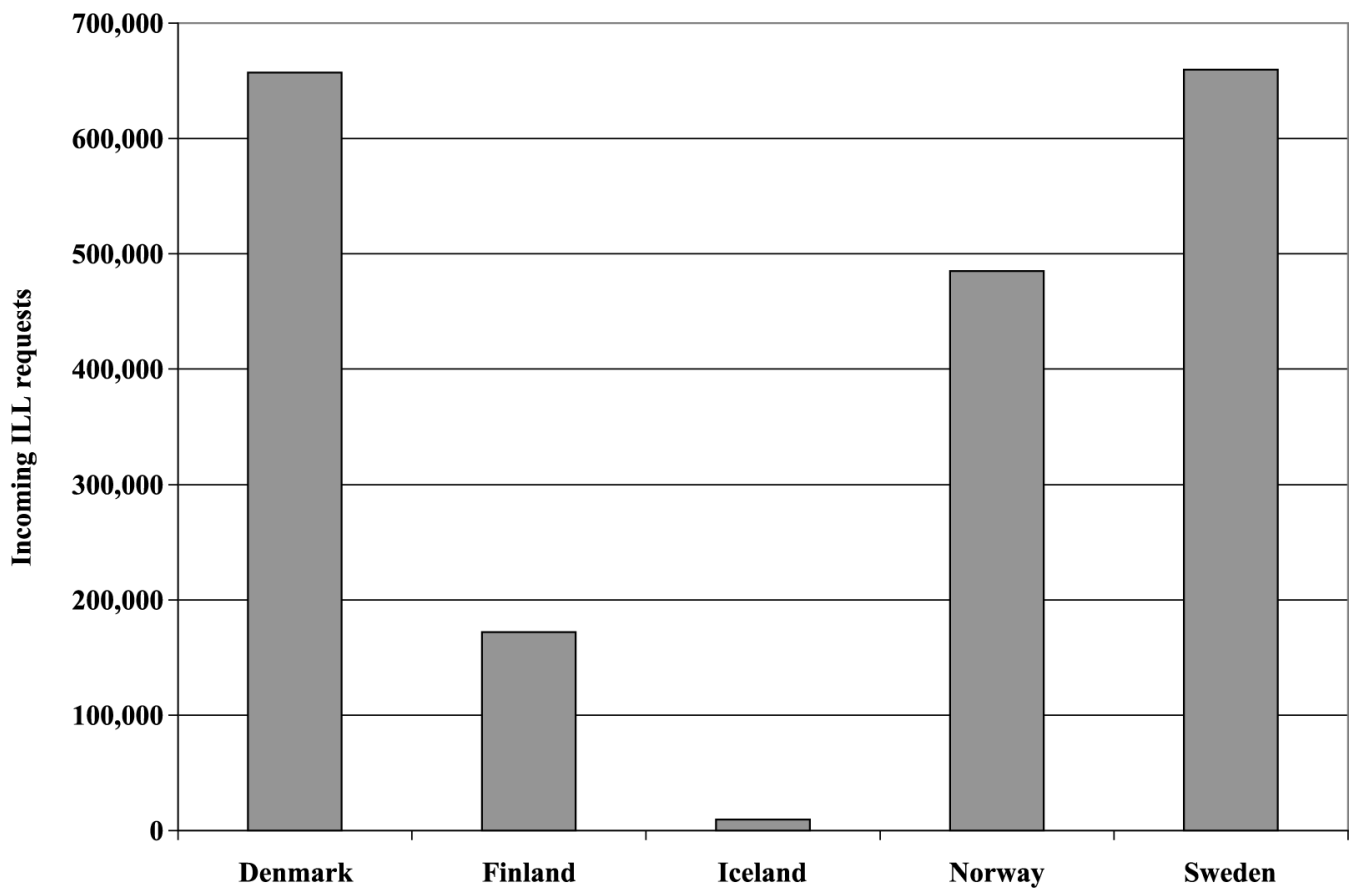

Source: Vattulainen (2003)

Table I Comparison of ILDS within the Nordic countries (Vattulainen, 2003)

\begin{tabular}{lccc}
\hline Country & $\begin{array}{c}\text { ILDS vs } \\
\text { home loans, \% }\end{array}$ & $\begin{array}{c}\text { Share of books } \\
\text { in ILDS, \% }\end{array}$ & $\begin{array}{c}\text { Combined unit } \\
\text { costs, euro }\end{array}$ \\
\hline Denmark & 13.7 & 53.1 & 16.47 \\
Finland & 1.8 & 24.1 & 21.52 \\
Iceland & 5.9 & 24.6 & 27.02 \\
Norway & 13.7 & 50.4 & 18.55 \\
Sweden & 10.2 & 47.9 & 20.86 \\
\hline
\end{tabular}

Current ILDS literature clearly shows that patron initiated requests are faster and cheaper (measured by unit costs) than traditional methods (see for example, Jackson et al. (2004)).

Nowadays it is easy for the user to locate the needed item. The system prevents impossible requests and thus improves the fill rate. Many users are already willing to do the requesting themselves and they should be given the possibility to do so. The user should also be able to follow the status of the request through a web page.

The union catalogue Linda is the locating tool for finding material in Finnish university libraries but it needs to provide an ILDS facility. Another solution would be to use the new Nelli-portal. This is the national electronic library interface which allows a user to search multiple databases simultaneously. It should allow mediated requesting using SFX and a web based ILDS form.

It is also evident that an integrated ILDS system is needed to streamline the work processes. However, there are few systems that fulfil the needs of Finnish libraries. Most software is developed in the USA for its own market and needs. The Finnish libraries have their own very decentralized way of doing ILDS as well as fee handling which differs from the American routines considerably. On the other hand, it is not likely that any of the Finnish software companies would develop an ILDS system, because the market is so small. Fortunately Finnish libraries using Voyager ILS do have one good solution for resource sharing: the universal borrowing (UB) module of Voyager.

\section{Universal borrowing (UB)}

Voyager's universal borrowing (UB) function provides a structure for unmediated, reciprocal borrowing of returnables in a Universal Catalog setting or between Voyager libraries. It allows libraries to integrate their collections for circulation purposes and to share the patron data. According to its basic philosophy UB is patron initiated and unmediated. Patrons of participating libraries can request and borrow material from any library within the consortium, and also return the books to any library. Patrons can go to any UB library and check books out using their home library's card. The system automatically fetches the patron information from the home library and keeps it in the visiting library's database until the books are returned. All transactions are tracked in real time and the patron can follow the status of his or her requests, loans and possible fines and fees through the web interface.

The use of the UB requires a fair amount of configurations in each participating database. However, this leads to great flexibility for libraries. It's the politics that is the hard part. A lot of mutual decisions have to be made in order to make UB a sensible and usable functionality among the participating libraries. 


\section{Linnea2 Consortium ILDS working group recommendations}

The Linnea2 Consortium ILDS working group presented its report to the General Council of the Consortium in April 2005. The group recommended that:

- the UB functionality should be implemented within the whole consortium as soon as possible;

- the consortium should purchase a suitable ILDS software package; and

- the reciprocal invoicing system within Finland should be improved.

The consortium libraries could handle most of their reciprocal ILDS traffic with UB. This would ease the work considerably. However, a notable share of requests has to be routed to libraries outside the consortium and good ILDS software is needed to deal with these. The candidates should be evaluated as soon as possible. The software should allow user initiated, unmediated requesting, it should support standards, and it should be able to handle routines such as sending requests, request follow-up and invoicing.

The results of the report have already seen action. The Linnea2 Consortium decided to form a new working group to continue the search for ILDS software. The task of the group is to look for possible solutions as well as to compile an RFP (Request For Proposal) for the system. The group has seen demonstrations of several ILDS systems. And the draft for the $\mathrm{RFP}$ is in preparation. The next meeting of the Linnea2 Consortium General Council will be in April, 2006. If a decision is taken to start procurement for a joint ILDS system for the consortium, it will be initiated shortly after this meeting.

Another working group has looked at the political issues of the universal borrowing module This group recommended that the UB should be implemented in all Linnea libraries and unmediated requesting should be allowed. However, the group suggested that a service fee should be charged for the UB loans. The proposal was accepted by the General Council in September. Some libraries have already started a UB service for their patrons, while many others are making plans.

\section{Conclusion}

ILDS in the Finnish university libraries is diminishing. Comparison to the Nordic countries shows that there are some structural problems affecting this in addition to the global changes in the scientific communication and in the ordering behaviour of the libraries. The recommendations of the Linnea2 Consortium working group have been taken seriously and some actions have already been done. It's time to forget about the old fashioned card catalogue-based "from library to library" thinking and leap to the new patron initiated world.

\section{Notes}

1 www.nrl.fi/english/index.html

2 www.lib.helsinki.fi/finelib/english/index.html

\section{References}

Hormia, K. (2004), "Developing the digital library as part of the information society", paper presented at the Digital Library Advance the Efficiency of Knowledge Utilization Conference, Beijing, 6-8 September.

Jackson, M.E., Kingma, B. and Delaney, T. (2004), "Assessing ILL/DD services: new cost-effective alternatives", ARL Biomonthly Report, Nos 230/231.

Kurikka, A.-M. and Liinamaa, M. (1972), "Kotimaisen kaukopalvelun opas (in Finnish)", Tieteellisten kirjastojen lautakunta, Helsinki.

Törnudd, E. (1993), Evaluation of the Resource Library System in Finland, Helsinki University of Technology Library, OTA-kirjasto A 17, Otaniemi.

Vattulainen, P. (2003), "Performance of interlending in Nordic academic libraries", report for NORDINFO Board, available at: http://inet.dpb.dpu.dk/nvbf/perform. pdf (accessed 15 February).

\section{About the authors}

Ari Muhonen is the Library Director at the Helsinki University of Technology Library. He is also the Chairman of the Linnea2 Consortium Steering Group as well as the Chairman of the Council for Finnish University Libraries. Ari Muhonen is the corresponding author and can be contacted at: Ari.Muhonen@tkk.fi

Annu Jauhiainen is the Deputy Director of Information Technology at the National Library of Finland. She is also the coordinator of the Linnea2 Consortium.

Pentti Vattulainen is the Director of the National Repository Library, Kuopin, Finland. 